\title{
Observations and linear analysis of sill-generated internal tides and estuarine flow in Haro Strait
}

\author{
Rich Pawlowicz \\ Department of Earth and Ocean Sciences, University of British Columbia, Vancouver, B.C., Canada \\ Received 21 June 2000; revised 12 September 2000; accepted 7 November 2001; published 25 June 2002.
}

[1] Current meter records from two sets of observations 20 years apart in Haro Strait, British Columbia, Canada, are analyzed. Haro Strait is a deep channel separated from larger bodies of water on either side by relatively shallow sills. The estuarine flow in this region is in approximate geostrophic balance and is apparently unaffected by the tidally driven spring/neap cycle in vertical stratification. Strong baroclinic variability with an amplitude $1 \mathrm{~m} \mathrm{~s}^{-1}$ (close to the amplitude of the barotropic tide) is present. A linear theory for internal tides in silled basins is developed using no-bottom-flow boundary conditions to represent sill effects. By comparison with observations it is concluded that an internal tide is generated at the seaward sill and propagates inshore. Although local damping appears to be weak, no return signal is found from the inshore sill, suggesting that either dissipation is strong in that area or that the internal tide is transmitted across that sill. INDEX TERMS: 4235 Oceanography: General: Estuarine processes; 4544 Oceanography: Physical: Internal and inertial waves; 4203 Oceanography: General: Analytical modeling; KEYWORDS: phase, spring/neap, ellipse

\section{Introduction}

[2] Although a meand surface outflow and deep inflow are required to maintain stratification in an estuary, the mechanisms by which water masses are modified and salt is transported may involve unsteady, albeit regular, tidally forced motions. Tidal cycles themselves are usually the strongest signal in time series derived from moored instruments. The relatively rapid tidal timescales can cause aliasing problems when standard shipboard observational techniques are employed. It is often difficult to generate a suitably "instantaneous" view of the physical state of a given area, especially when internal variability is strong. On the other hand, tidal forcing is inherently deterministic and follows predictable patterns, and so it is possible that the products of such forcing can assume deterministic and predictable temporal patterns. It may then be possible to combine observations made during different days and even different seasons in order to synthesize an understanding of the total physical state of a given area.

[3] In this paper the summertime internal motions in a unique and complex estuarine system are described using two sets of observations taken 20 years apart. This system is characterized by the presence of two sills some $50 \mathrm{~km}$ apart, separating deeper basins. Tidal velocities are on the order of 1-2 $\mathrm{m} \mathrm{s}^{-1}$. Mean flows are consistent with estuarine dynamics and consist of a surface outflow and a deep inflow. Over fortnightly scales the vertical stratification is modulated by the spring/neap cycle of available tidal energy. At tidal timescales the interaction of the barotropic

Copyright 2002 by the American Geophysical Union. 0148-0227/02/2000JC000504\$09.00 tide with the sill results in a large internal signal within the basin. It is shown that the motions are consistent with generation of a propagating internal wave at the larger sill, with only weak local damping. The amplitudes of isotherm displacements are large but not inconsistent with the forcing, and there is no evidence of a resonant or near-resonant basin mode. Since the basin is short, this implies that either dissipation is strong at the northern end or that the northern sill does not provide a strong barrier for the internal motions. Although the linear model can explain many of the observed features, it is clear that the amplitude of the motions is large enough that nonlinear effects must be strong; analysis of such effects will appear elsewhere.

\section{Oceanographic Background}

[4] The Strait of Georgia is a large open body of water (200 km long by $30 \mathrm{~km}$ wide with depths of up to $400 \mathrm{~m}$ ) that empties into the Pacific Ocean to the south of Vancouver Island through the relatively simple geometry of the Strait of Juan de Fuca (20 km wide, $100 \mathrm{~km}$ long, and $200 \mathrm{~m}$ deep), which is itself joined to the Pacific Ocean by a canyon cutting through the continental shelf (Figure 1). However, the connection between the two Straits is interrupted by a complex region of islands and channels, the largest of which is Haro Strait. This deep channel, with a width of about $10 \mathrm{~km}$ and depths of up to $350 \mathrm{~m}$, is separated from its neighbors by a broad area of shallow water southeast of Vancouver Island called the Victoria Sill and a more abrupt sill to the north in Boundary Pass. Saddle depths are slightly greater than $100 \mathrm{~m}$ in both cases. The topography of Haro Strait is asymmetric, with a steep 

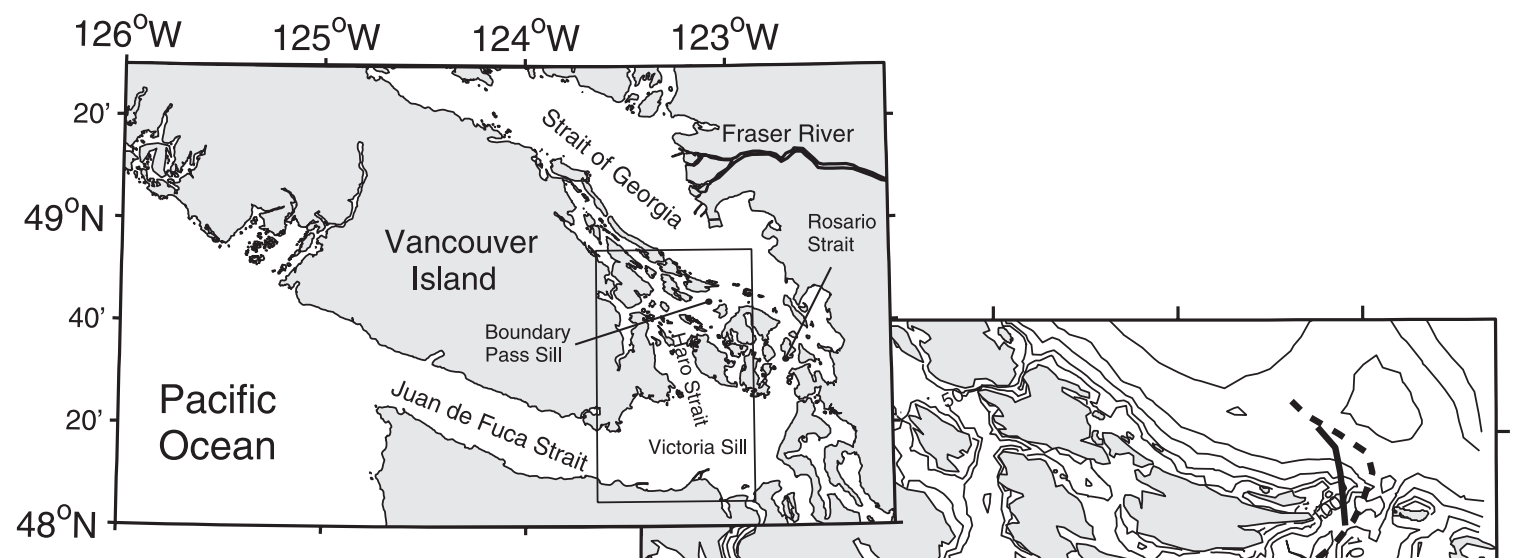

a)

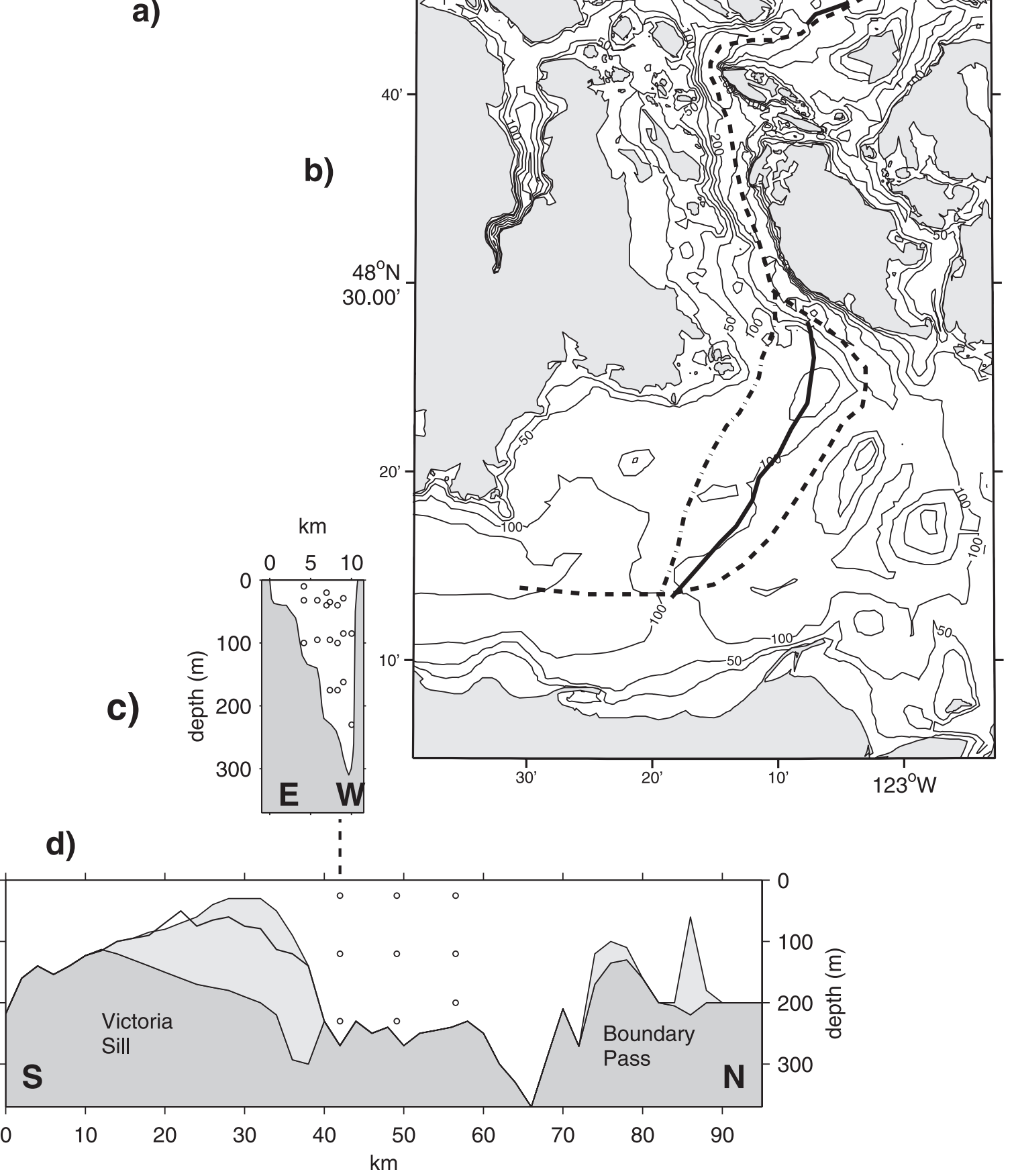


boundary on the eastern side for much of its length and more gradual, stepped, slopes on the western side (Figure 1c). In order to approach the Boundary Pass sill the main channel makes a sharp eastward bend. Directly to the north of this bend, the waters shoal into a network of relatively sheltered and isolated channels that are generally $50 \mathrm{~m}$ or less in depth. Even in this quieter region, however, there are two locations at which depths are greater than $200 \mathrm{~m}$.

[5] The Victoria Sill is irregular and asymmetric. Its western slopes rise relatively smoothly to a saddle depth of $110 \mathrm{~m}$. To the east and northeast of this saddle the topography rises to a series of banks with depths less than $20 \mathrm{~m}$ and also drops in a series of channels that eventually drain into Haro Strait. A shallow channel close to Vancouver Island drops steeply, but other channels curve farther eastward and drop more gradually. The channel axis (i.e., the main path of flow) is not obvious, and several possible choices are shown in Figure 1b, with bathymetric relief along each illustrated in Figure 1d. Although one might expect the deeper channels to be important for the estuarine flow, results from a constant density tide model [Foreman et al., 1995] suggest that much of the tidal energy flux for the $\mathrm{M}_{2}$ tide passes over the shallow regions of the sill. The Boundary Pass Sill is more straightforward, but inshore of this sill the channel is partially blocked at the entrance to Strait of Georgia by a steep-sided ridge that extends across half the channel (illustrated in Figure 1d).

[6] The overall bathymetry is thus extremely complicated, and it is not clear how one might physically idealize this region. It is also not clear if any one idealization would suffice for all purposes. It is easily possible to imagine that mean flows travel along pathways different than those important for tidal motions.

[7] On the other hand, the general description of the estuarine circulation over the entire region is well known [Herlinveaux and Tully, 1961; Thomson, 1981; Pawlowicz, 2001]. In the summer, snow melt in the mainland interior provides $\approx 10^{4} \mathrm{~m}^{3} \mathrm{~s}^{-1}$ of fresh water to the Strait of Georgia, forming a fresh and warm upper layer with a depth of about $10 \mathrm{~m}$. This fresh water exits the strait on both sides of Vancouver Island, to the north through Johnstone Strait and to the south via Haro Strait. The vigorous tidal motions in these channels result in mixing and dilution of the fresh layer, so that the surface outflow in the Strait of Juan de Fuca occupies a much greater portion of the water column, with interface depths down to $100 \mathrm{~m}$ on the northern side of the strait. The southern part of the circulation around Vancouver Island has received the most attention, partly because previous work indicated that the layer transport in the Strait of Juan de Fuca, of order $10-20 \times 10^{4} \mathrm{~m}^{3} \mathrm{~s}^{-1}$ is rather larger than the $3 \times 10^{4} \mathrm{~m}^{3} \mathrm{~s}^{-1}$ that occurs in Johnstone Strait. Recent work, however, suggests that much of this flow results from entrainment and recirculation of deeper water within the Haro Strait and that the actual outflow from the Strait of Georgia is much smaller (see discussion by Pawlowicz and Farmer [1998]). Note that the deep inflow is rather directly connected to the deep Pacific Ocean through Juan de Fuca Canyon, bypassing the continental shelf. The dynamics of Haro Strait are thus important in controlling the overall oceanography of this region, not only because of its role in controlling the estuarine circulation but also because it provides an important mechanism by which nutrients from the deep Pacific Ocean are brought to the surface [Crawford, 1991; Pawlowicz, 2001].

[8] Another, smaller channel (Rosario Strait) also links the Straits of Georgia and Juan de Fuca. This channel is much shallower (with a saddle depth of $50 \mathrm{~m}$ ) and more convoluted than Haro Strait, and it is thought that the throughflow here is minimal.

[9] Oceanographic investigations in the Haro Strait region have generally been confined to process studies of turbulent mixing processes [e.g., Gargett and Moum, 1995; Farmer et al., 1995, 2002]. The effect of these processes on the large-scale circulation has when necessary been parameterized in some bulk fashion [e.g., LeBlond, 1994], and it is known through such studies that a marked spring/neap cycle of mixing occurs governed by the fortnightly variability in available tidal energy but also affected by winddriven changes in the stratification of inflowing waters [Griffin and LeBlond, 1990]. Here we attempt to understand more directly the internal motions of water masses due to estuarine and tidal forcing.

\section{Mean Flows}

[10] Although there is a lack of detailed knowledge about the dynamics of Haro Strait, observational efforts have been made in the past. In 1976 a large array of current meters and thermistor strings was deployed across the strait [Webster, 1977]. Positions are shown in Figures $2 \mathrm{a}-2 \mathrm{c}$ and 1c. Observations are divided into three depth ranges: nearsurface $(0-50 \mathrm{~m}$, nominally $25 \mathrm{~m})$, midwater $(50-150 \mathrm{~m}$, nominally $100 \mathrm{~m})$, or deep (>150 m, nominally $200 \mathrm{~m})$. Plotted in Figure 2 are progressive vectors of the measured currents at each instrument, normalized by record length so that the total displacements are an indication of mean currents according to the scale shown. In general, the progressive vectors are fairly straight, indicating that subtidal flows tend to be aligned in a particular direction. Surface instruments show a southward estuarine outflow, and deep instruments show an inflow to the northwest along the channel axis. Midwater instruments show inflow on the eastern side of the array and outflow on the western side. As in the Strait of Juan de Fuca, the interface between deep inflowing water and surface outflow slopes downward toward Vancouver Island as a consequence of the Coriolis

Figure 1. (opposite) (a) An overview of the general features and bathymetry surrounding Haro Strait. (b) A detailed map of the complex bathymetry and geometry of the Haro Strait region. Thick curves indicate various possible channel axes. The easternmost possibility is the deepest but is also the most indirect. (c) Bathymetry across Haro Strait north of the Victoria Sill, with locations of the moored instruments in 1976 shown by open circles. (d) Bathymetry along Haro Strait, with location of moored instruments in 1996 shown by open circles. At each sill the various curves illustrate the variability in cross-channel depths using the different channel axes shown in Figure $1 \mathrm{~b}$. 


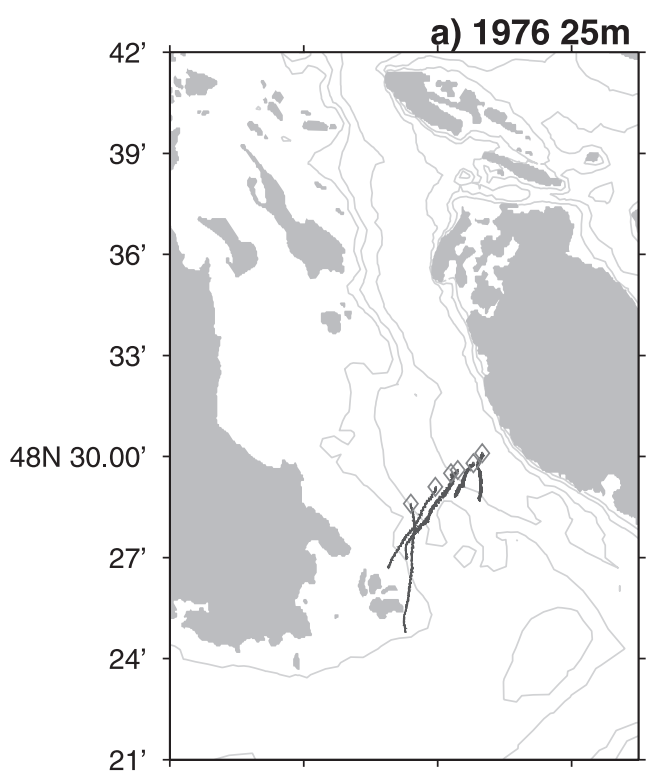

b) $1976100 \mathrm{~m}$

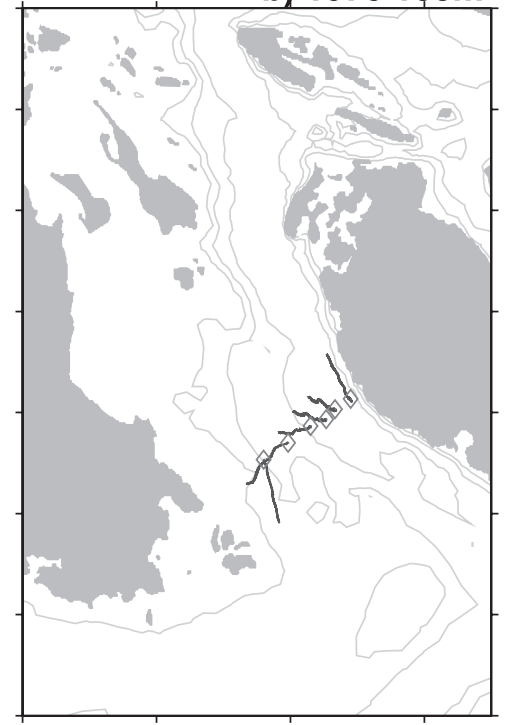

$\stackrel{\mathrm{cm} / \mathrm{s}}{ }$ c) $1976200 \mathrm{~m}$

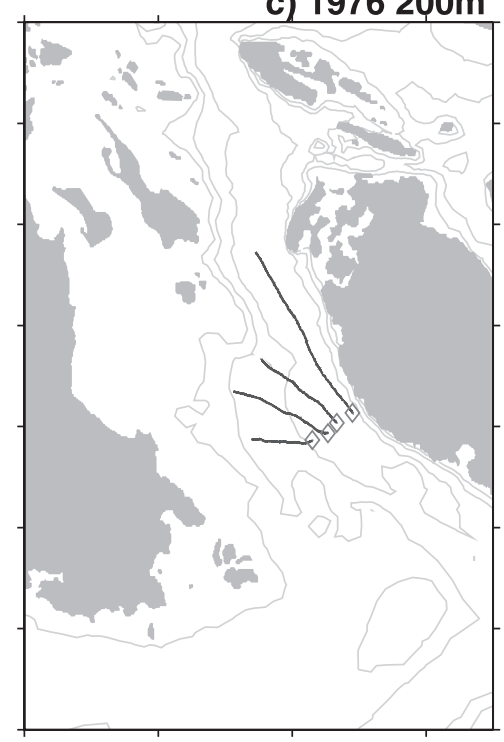

e) $1996100 \mathrm{~m}$

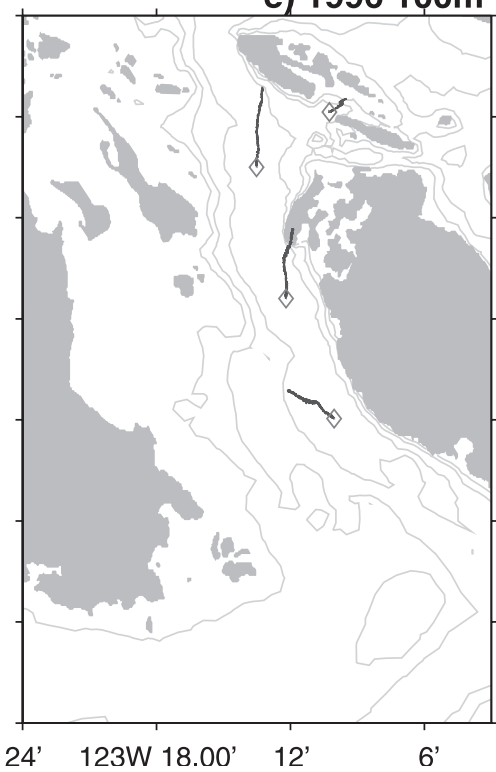

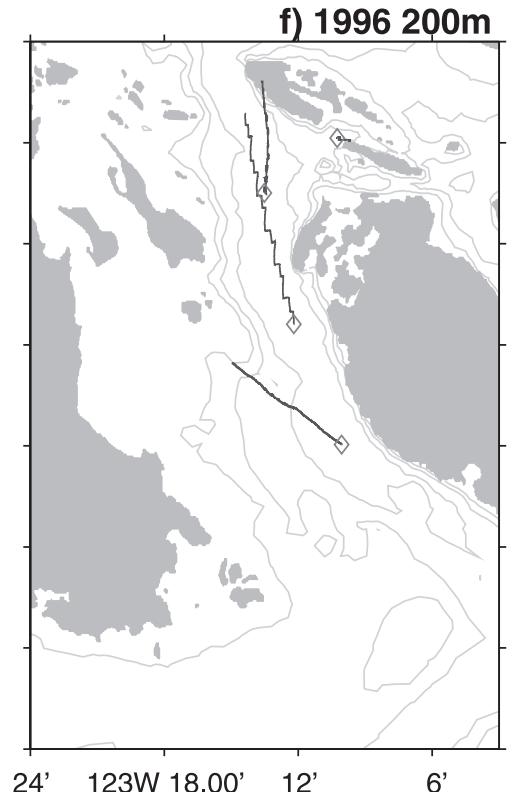

f) $1996200 \mathrm{~m}$

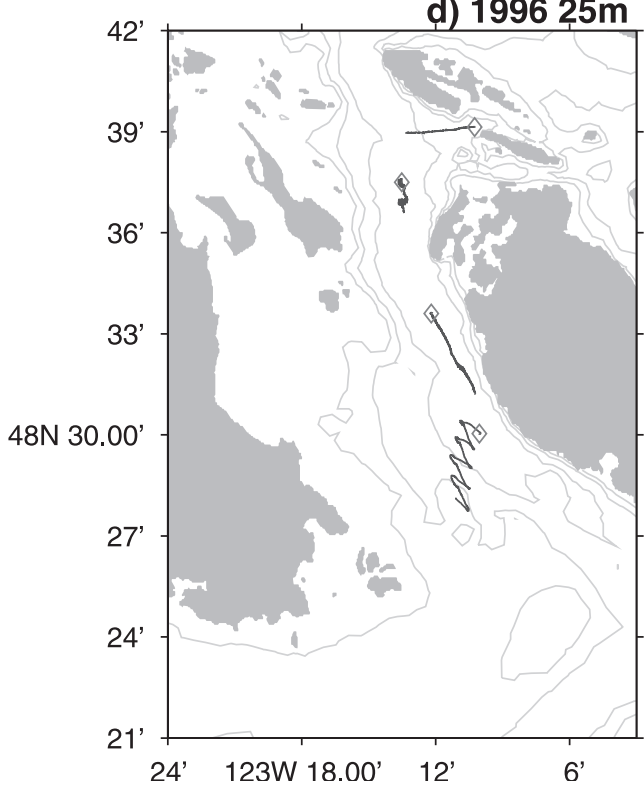

Figure 2. Location of current meters with respect to areal features from (a) shallow, (b) midwater, and (c) deep 1976 measurements and from (d) shallow, (e) midwater, and (f) deep 1996 observations. Measured velocities are shown as progressive vector diagrams with total lengths normalized by time so that mean currents can be read using the scale provided.

effect. In order to balance an observed gradient in vertical velocity of $50 \mathrm{~cm} \mathrm{~s}^{-1}$ in $200 \mathrm{~m}$ (Figure 3b) a thermal wind balance,

$$
f \frac{\partial v}{\partial z} \sim \frac{g}{\rho_{0}} \frac{\partial \rho}{\partial x}
$$

requires that cross-channel density changes be of order $0.2 \mathrm{~kg} \mathrm{~m}^{-3}$ over $10 \mathrm{~km}$. Observed density gradients appear to be of this order, but more precise comparison is precluded by offset problems in instrument calibration.

[11] Mean velocities change gradually rather than abruptly with depth. Strongest flows occur near the side and bottom boundaries of the channel, and so in spite of the large number of instruments in the array, it is difficult to judge the balance between inflow and outflow, i.e., the net transport [Pawlowicz and Farmer, 1998]. This has generally been true for all attempts using direct measurements of 

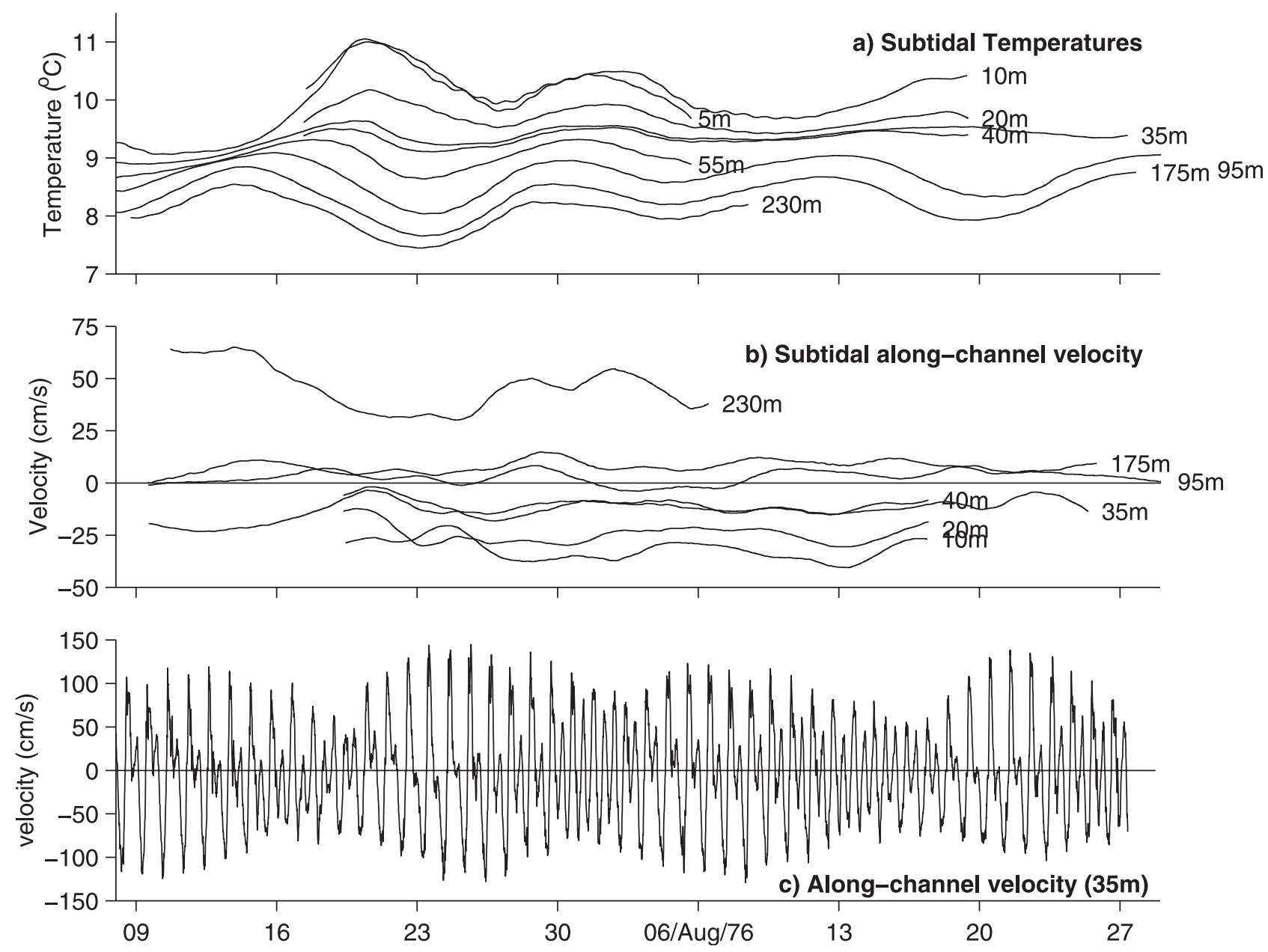

Figure 3. Spring/neap cycling in Haro Strait. (a) Low-pass-filtered temperature records for a variety of instruments. The instrument depth is labelled to the right of the curve. (b) Low-pass-filtered alongchannel flow. (c) Observed tidal velocities at $35 \mathrm{~m}$ (northward flooding velocities are positive). Note the 2 week spring/neap cycle in tidal amplitude.

currents in this estuarine system [e.g., Thomson, 1976; Godin et al., 1981].

[12] A more limited mooring program took place in the summer of 1996 (Table 1 and Figure 1). Instruments were placed along the channel rather than across it. The direction and magnitude of mean currents are shown in Figures $2 \mathrm{~d}-$ $2 \mathrm{f}$. The instruments are again categorized as near-surface, midwater, or deep. The southernmost 1996 mooring was colocated with a 1976 mooring, and mean currents from both years are very similar. The line showing near-surface outflow from this southernmost mooring appears jagged because the record is relatively short (4 days) because of a rotor loss. The daily variations are thus more prominent relative to the cumulative drift. The general pattern of surface outflow and deep inflow is seen at all moorings.

\section{Spring/Neap Cycling}

[13] Figure 3a shows temperature records at selected depths from both current meters on subsurface moorings and thermistor strings deployed below surface floats in the 1976 program. Temperature and salinity are strongly corre- lated so the pattern of salinity (and density) changes is almost identical. An increase of $1{ }^{\circ} \mathrm{C}$ corresponds to a density decrease of about $0.9 \mathrm{~kg} \mathrm{~m}^{-3}$. Records have been low-pass-filtered with a cutoff period of 2 days to remove tidal variability of about $1^{\circ} \mathrm{C}$. There is a marked fortnightly cycle in vertical stratification that is related to spring/neap cycling in tidal velocities. The timing of the spring/neap cycle can be identified from the along-channel velocity record shown in Figure 3c. In general, when tidal velocities are large, the stratification decreases. The opposite occurs when velocities are small.

[14] However, although the vertical mixing is modulated, the estuarine flow itself does not appear to be affected by the spring/neap cycle in the manner suggested by Linden and Simpson [1988]. Figure 3b shows low-pass-filtered along-channel currents at selected depths. Northward velocities are positive. Although there is some variability in these records, it is not as regular nor is it as pronounced as that seen in the vertical stratification. No relationship was found between variability in cross-channel density gradients (not shown) and either the spring/neap cycle or the alongchannel currents. 
Table 1. 1996 Haro Strait Current Meter Program ${ }^{\text {a }}$

\begin{tabular}{|c|c|c|c|}
\hline $\begin{array}{c}\text { Instrument Seria } \\
\text { Number }\end{array}$ & $\begin{array}{l}\text { Depth, } \\
\text { m }\end{array}$ & $\begin{array}{c}\text { Deployment } \\
\text { Date }\end{array}$ & $\begin{array}{l}\text { Record Length, } \\
\text { days }\end{array}$ \\
\hline \multicolumn{4}{|c|}{ Mooring $S: 48^{\circ} 30.04^{\prime} \mathrm{N} 123^{\circ} 10.05^{\prime} \mathrm{W}, 271 \mathrm{~m}$} \\
\hline 3684 & 25 & 16 June 1996 & 24 (4 days speed) \\
\hline 5093 & 120 & 16 June 1996 & 24 \\
\hline 2525 & 231 & 16 June 1996 & 24 \\
\hline \multicolumn{4}{|c|}{ Mooring M: $48^{\circ} 33.60^{\prime} \mathrm{N}, 123^{\circ} 12.20^{\prime} \mathrm{W}, 270 \mathrm{~m}$} \\
\hline 314 & 25 & 12 June 1996 & 28 \\
\hline 6938 & 120 & 12 June 1996 & 28 \\
\hline 1935 & 230 & 12 June 1996 & 28 (6 days speed) \\
\hline \multicolumn{4}{|c|}{ Mooring $N: 48^{\circ} 37.50^{\prime} \mathrm{N}, 123^{\circ} 13.51^{\prime} \mathrm{W}, 242 \mathrm{~m}$} \\
\hline 7893 & 25 & 16 June 1996 & 24 \\
\hline & 120 & 16 June 1996 & 24 \\
\hline 3695 & 202 & 16 June 1996 & 24 ( 9 days speed) \\
\hline \multicolumn{4}{|c|}{ Mooring E: $48^{\circ} 39.14^{\prime} \mathrm{N}, 123^{\circ} 10.25^{\prime} \mathrm{W}, 133 \mathrm{~m}$} \\
\hline 736 & 25 & 12 June 1996 & 28 \\
\hline 7897 & 70 & 12 June 1996 & 28 \\
\hline 3503 & 123 & 12June 1996 & 28 \\
\hline
\end{tabular}

${ }^{\text {a }}$ All meters are Aanderaa RCM-4. Strong currents resulted in the loss of several rotors early in the deployment so that some velocity records are quite short.

[15] Finally, note that the degree to which mixing during spring tides homogenizes the water column is not the same for each cycle. Griffin and LeBlond [1990] show that strong pulses of fresh water can be observed in records of surface salinity west of the Victoria Sill. They explain the presence of this pulse by suggesting that a critical cutoff mechanism applies to mixing here, such that increased stratification in Boundary Pass due to northerly winds in the Strait of Georgia can suppress tidal mixing and allow fresh water to pass through the system relatively unmixed. One such fresh pulse can be seen around 20 July in Figure 3a and also in Figure 9 by Griffin and LeBlond [1990].

\section{Internal Tides}

[16] At tidal timescales there is a marked variability in water column properties with a complex spatial structure. Velocities at different locations are not in phase, and the difference appears to change even over a day with the strength of the tide. This is further complicated by the nature of the tide, which usually consists of one strong ebb/flood and one weak ebb/flood in every day (see Figure 3c).

[17] Figure 4a shows near-surface and deep along-channel currents in Haro Strait during the summer of 1976. The two (carefully selected) time series are quite different, but the following decomposition, suggested on the basis of the analysis described later, is instructive. First, we subtract time means (i.e., the estuarine circulation) and form a halfsum and half-difference time series from these two records. The new time series are very similar (Figure 4b); indeed, if
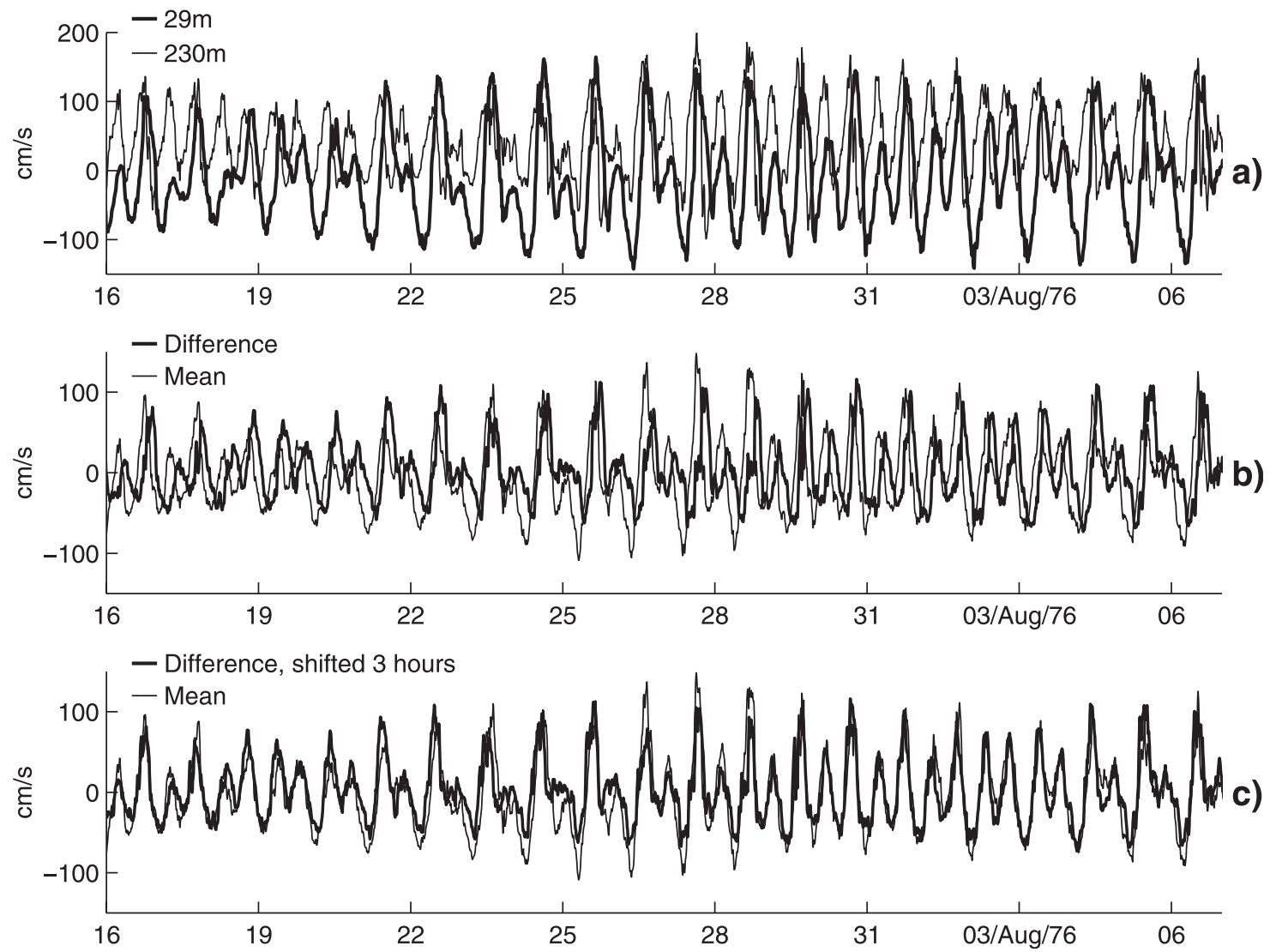

Figure 4. (a) Along-channel velocities near the surface and near the bottom. (b) Sum and Difference of the two time series. (c) Sum and difference with time mean subtracted and difference series aligned 3 hours leftward. 


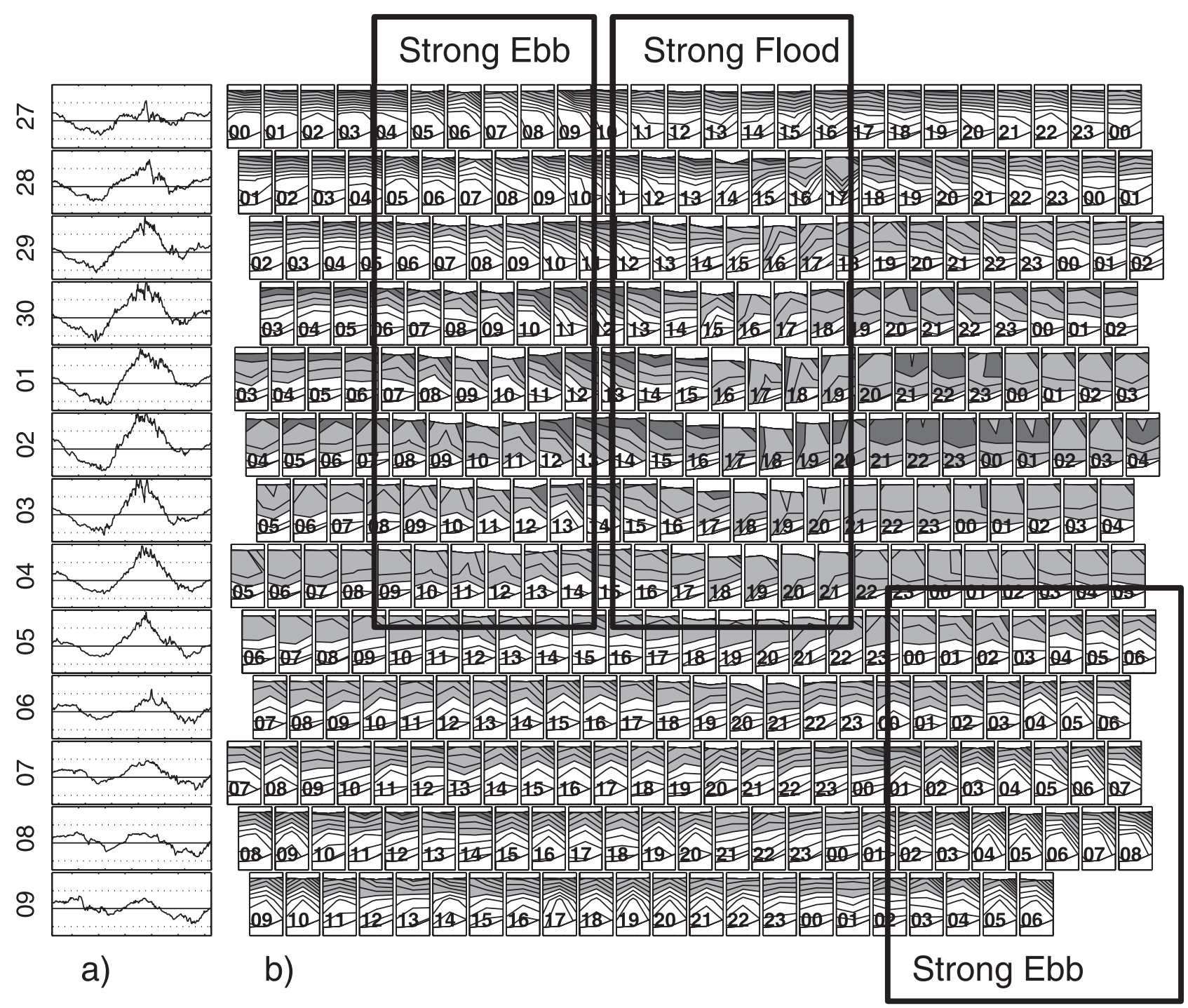

Figure 5. Hourly averaged vertical sections of along-channel temperature for a 2 week period from 27 June to 9 July 1996. (a) Observed currents for consecutive 24 hour 42 min periods for dates indicated on the left-hand side. (b) Each row contains 25 subplots, each of which shows the mean vertical and along-channel temperature field for the hour labelled (contour interval $0.25^{\circ} \mathrm{C}$ ). The vertical axis of each subplot represents depths from 0 to $270 \mathrm{~m}$. Mooring $\mathrm{S}$ is at the left edge, and mooring $\mathrm{N}$ is at the right edge of each subplot. Subplots showing maximum currents in subsequent days are thus vertically aligned. Rows correspond with currents displayed in Figure 5a. The dark outlines encompass periods of strong flow. Spring tides occur around the 30 June.

we advance the half-difference signal by 3 hours, they are virtually identical (Figure 4c). If we identify the half-sum time series as an estimate of the barotropic tidal signal and the half-difference as an estimate of a first baroclinic mode, this suggests the presence of a strong internal tide.

[18] The relatively short wavelengths of the lowest internal mode (about 20-40 km for typical stratification) suggest that coherent along-channel structure should be observable in velocity and density fields. In 1996, moorings were placed at three different locations along the channel (and one outside the channel (see Figures 1 and 2 and Table 1). Each mooring was equipped with three Aanderaa RCM-4 current meters. Unfortunately, the rotors on three of the instruments were lost within a few days, and the velocity records on other instruments are of low quality, especially during periods of strong currents, apparently because of strumming problems. Sum and difference time series exhibit the same general qualities discussed above, but the correspondence is less convincing. Instead, in Figure 5 the mean temperature field in a vertical along-channel section constructed from the $3 \times 3$ instrument grid is shown for hourly blocks of time. Each box thus represents the hourly averaged temperature field over an along-channel distance of $14.4 \mathrm{~km}$ and a depth of $300 \mathrm{~m}$. Each row contains 25 hours of data, and subsequent rows are offset slightly so that the peak tides, which occur about 42 min later each day through springs, are aligned vertically (an abrupt shift in this progression occurs during neaps). Their general time period 
is indicated by the large rectangular box outlines. Largest spring tides occur near 1 July. When presented in this way, it is obvious that the baroclinic field varies with surprising regularity. During strong ebbs the temperature isotherms begin to slope upward to the south. Strong floods are associated with a relaxation of the southward slant and transition to a northward slant. During the weak tides, isotherm slope changes are much less extreme. At any particular stage in the tide (i.e., along points on a vertical through Figure 5), isotherm slopes are greater near spring tides and lesser near neaps. At the same time there is a decrease in the number of contour lines toward spring tides, indicating the decrease in stratification and an increase during neaps. This is most visible on the right-hand side of Figure 5. The isotherm displacements strongly suggest the presence of low mode number internal wave.

[19] For further insight a harmonic analysis was carried out for currents at different depths in the deepest part of the channel using the 1976 observations. The resulting tidal ellipses are narrow (semiminor axes are about 1 order of magnitude shorter than semimajor axes) and are inclined in the along-channel direction. Flows are thus predominantly along the channel axis with little rotational tendency.

[20] Figure 6 shows the ellipse semimajor axes amplitude $A$ and Greenwich Phase $G$ for the four most significant components of the analysis. The amplitudes of the diurnal $\mathrm{O}_{1}$ and $\mathrm{K}_{1}$ components generally decrease with depth. On the other hand, the amplitude of the semidiurnal components $\mathrm{M}_{2}$ and $\mathrm{S}_{2}$ have a minimum at middepths. The Greenwich phase (the phase of the local response in comparison to the phase of the forcing at a reference longitude of $0^{\circ}$, defined such that a larger angle implies later arrival of wave crests) tends to decrease roughly linearly with depth for all constituents with bottom currents leading surface currents by about 3 hours. In the theoretical analysis carried out in section 6 it is shown that plotting the depth variation of the complex number $A \exp (i G)$ is a useful diagnostic for the internal behavior. Here we note only that such plots (Figure 6c) show the depth variations to lie roughly along a straight line in the complex plane, not too far from the origin. Harmonic analysis of the two longer records at the southern mooring in 1996 show that constituent amplitudes and Greenwich phases are generally consistent with those found in 1976, although uncertainties are much larger because of the shortness of the records and increased noise levels.

[21] The nearby Victoria Sill (see Figure 2d) is likely responsible for the generation of this tide. Intuitively, one expects that stronger (spring) tides should be associated with more intense baroclinic motions, but the fate of these internal waves as they propagate away from the sill is not clear. Not far to the north is a sharp bend in the channel (near Turn Point), and past that, the Boundary Pass sill, both of which could act as strong reflectors. Is the amplitude of the response explained by the presence of a resonant internal mode, or is dissipation strong enough that the internal signal does not reflect and return? If dissipation is important, is it widespread, or does it occur only in certain regions?

\section{Linear Analysis of the Internal Tide}

[22] The regularity of the baroclinic feature seen in Figure 5 and the relative simplicity of the results of harmonic analysis suggest that a simple dynamical system should be able to capture the essential physics of the process. Consider a stratified channel dominated by the barotropic and first baroclinic modes, in which a tidal signal propagates past two sills separated by a distance $L$ (Figure 7). For the situation considered here the wavelength of the barotropic mode is much greater than that of the baroclinic mode, and the isopycnal displacement due to the barotropic mode is much less than that due to the baroclinic mode. We therefore assume the wavelength of the barotropic mode to be essentially infinite and its isopycnal displacement to be negligible so the net velocity $u_{\mathrm{NET}}$ and displacement $\eta_{\mathrm{NET}}$ can be written

$$
\begin{gathered}
u_{\text {NET }}=u_{\text {BAROTROPIC }}+u \\
\eta_{\text {NET }}=\eta
\end{gathered}
$$

where $u_{\text {BAROTROPIC }}=u_{0} \exp (-i \sigma t)$ is the barotropic flow that oscillates with a tidal frequency $\sigma$. The magnitude of the complex number $u_{0}$ is the amplitude of the barotropic tide, and its angle is the Greenwich phase. The baroclinic velocity $u(x, z, t)$ and displacement $\eta(x, z, t)$ are functions of space as well as time and can be found for a channel of rectangular cross section by assuming linear shallow-water dynamics with a density field $\rho=\rho_{0}+\bar{\rho}(z)+\rho^{\prime}$ between the bottom at $z=0$ and the surface at $z=H$ :

$$
\begin{aligned}
u_{t} & =-\frac{p_{x}}{\rho_{0}}-R u, \\
0 & =-p_{z}-g \rho^{\prime}, \\
u_{x}+w_{z} & =0, \\
g \rho_{t}^{\prime}-\rho_{0} N^{2} w & =0, \\
\eta_{t} & =w,
\end{aligned}
$$

where $N^{2}=-g \bar{\rho}_{z} / \rho_{0}$ is the buoyancy frequency, which we take to be constant, $p$ is the pressure, $w$ is the vertical velocity, and the $x$ axis lies along the channel. Dissipation has been parameterized using a linear damping factor $R$. The effects of rotation have been ignored; implications of this will be discussed later. As the equations are linear, we can assume an $\exp (-i \sigma t)$ dependence in all variables.

[23] In the vicinity of even a simple sill the baroclinic behavior can have many forms [Baines, 1995]. The issue is further clouded here by the spatial complexity of the Victoria Sill and the time-varying nature of the forcing. However, we shall attempt to parameterize the overall effects of the topographic interaction in the following way. Since the effect of the sill will be to prevent the unimpeded flow of deep water, we assume that the tidal velocity near the bottom at the sill edge is approximately zero and all of the motion is in the upper part of the water column; that is, at $x=0, L$ we have

$$
\begin{array}{ll}
u=u_{0}, & z=H, \\
u=-u_{0}\left(\text { or } u_{\mathrm{NET}}=0\right), & z=0,
\end{array}
$$

the estuarine component of mean velocity being for the moment ignored. This is obviously a strong interaction. Similar boundary conditions have been used before for sill generation of internal tides in fjords [e.g., Stigebrandt, 

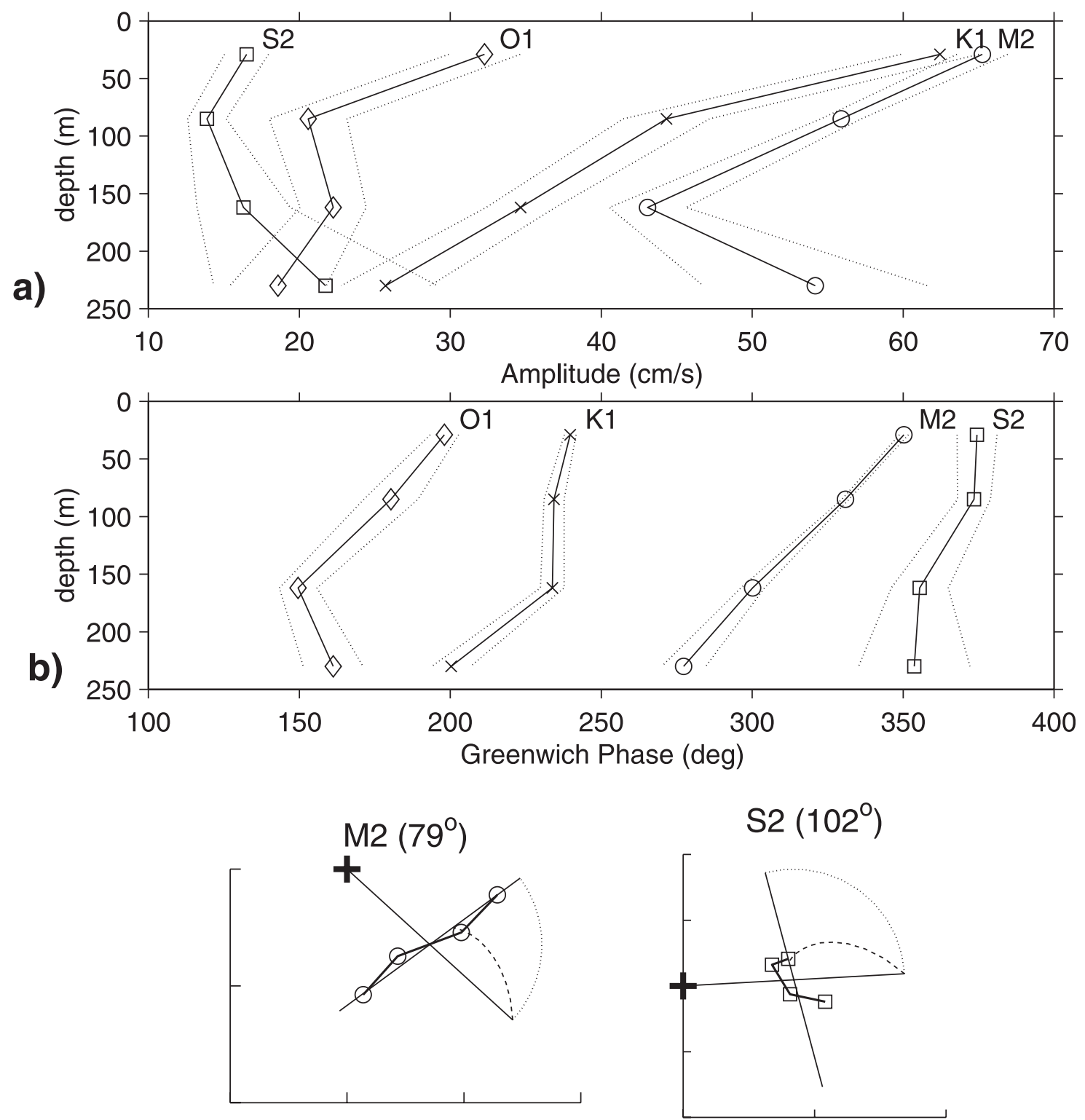

c)

$\mathrm{O} 1\left(58^{\circ}\right)$

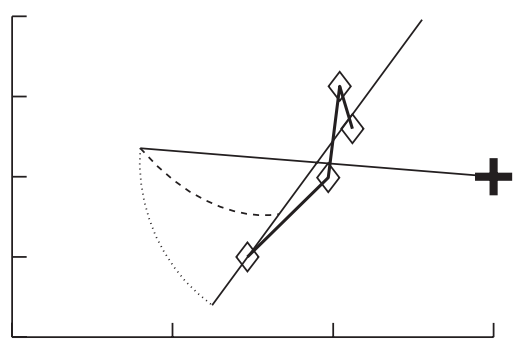

$\mathrm{K} 1\left(24^{\circ}\right)$

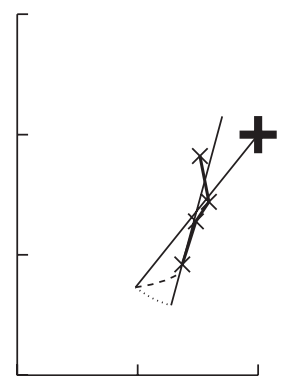

Figure 6. Harmonic analysis for observations in June/July 1976 taken from the easternmost instruments that were in the deepest part of the channel. Only the most significant four constituents are shown. (a) Ellipse semimajor axis amplitude. (b) Greenwich Phase. Dotted curves are 95\% confidence intervals. (c) Amplitude and phase plotted as complex vectors for all constituents. The origin is marked with a plus. Thin lines are the analysis according to linear theory. The solid line extending from the origin represents sill conditions according to the model and, after rotating by the angle indicated, approximately matches the observations. The dotted line shows the spatial evolution of an undamped surface response, and the dashed line shows the evolution of a strongly damped response (see text for details). Record lengths are $39,39,33$, and 31 days for the observations in order of shallowest to deepest. 


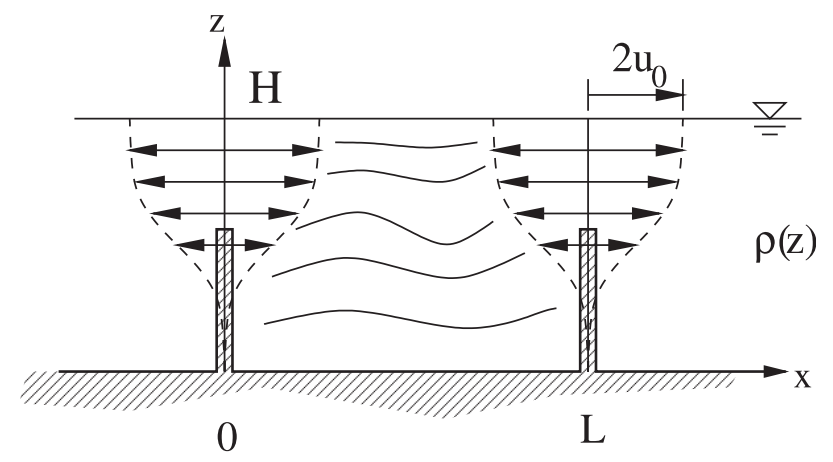

Figure 7. Conceptual model for baroclinic basin modes. At the sills $(x=0, L)$ the assumption that near-bottom flow is blocked provides the coupling between barotropic and baroclinic modes. Away from the sills the baroclinic signal propagates in both directions as a free wave.

1976; Stacey, 1985]. The theory can be extended in obvious ways to account for an incomplete blocking of the bottom flow, but the observations considered here are not comprehensive enough to justify such complications.

[24] Assuming horizontally propagating plane wave solutions proportional to $\exp (i k x)$, equation (4) reduces to

$$
w_{z z}+\frac{N^{2} k^{2}}{\sigma^{2}(1+i R \sigma)} w=0
$$

with boundary conditions $w(z)=0$ at $z=0, H$. Lowest-mode free-wave solutions for the horizontal velocity $u$ outside the basin are

$$
u=-u_{0} \cos \left(\frac{\pi z}{H}\right) e^{i k x}
$$

where the horizontal wave number $k$ is complex and given by

$$
k= \pm \frac{\sigma \pi}{N H} \sqrt{1+i \frac{R}{\sigma}}
$$

the positive root being used for $x>L$ and the negative root being used for $x<0$. The real part of $k$ expresses the spatially oscillating signal and the imaginary part an exponential decay. In the limit of large friction the real and imaginary parts have equal magnitude.

[25] In between the two sills $(0<x<L)$ the solution is composed of the sum of right and left going waves, and we have after some manipulation

$$
u=-u_{0} \frac{\sin (k x)-\sin [k(x-L)]}{\sin (k L)} \cos \left(\frac{\pi z}{H}\right)
$$

keeping in mind that $k$ may be complex.

[26] The spatial variation of the total velocity field can be understood in terms of the evolution of $u_{0}+u$, which is a complex number whose magnitude represents the amplitude of the total response and whose angle represents the Greenwich Phase of the total [Farmer and Freeland, 1983]. In particular, we consider the variations with depth of this sum at a particular $x$. Three cases are shown schematically in Figure 8. First, consider a standing wave response when dissipation is negligible. In this case the baroclinic velocity response is at a phase angle of either $0^{\circ}$ or $180^{\circ}$ compared to the barotropic forcing. Thus, in the complex plane the variation with depth must be collinear with the vector representing the barotropic signal $u_{0}$. The magnitude of the response may be greater or smaller than the magnitude of the barotropic signal depending on the degree to which a resonance is being forced (in this case, signified by the magnitude of $1 / \sin k L$ in equation (9)). If the internal response is a pure propagating wave, then the surface and bottom amplitudes appear at opposite ends of the diameter of a circle, which is centered on $u_{0}$ and touches the origin. This diameter is rotated through an angle $k x$ compared with the angle of the barotropic forcing. The magnitude of the response thus lies somewhere between 0 and $2\left|u_{0}\right|$ depending on the distance from the sill. If the signal is a damped wave, then the velocities appear on a rotating bar as before, but the length of the bar decays exponentially with a factor $\operatorname{Imag}\{k x\}$ as it rotates through an angle Real $\{k x\}$. In the limit of strong friction (large $R / \sigma$ ) the real and imaginary parts of $k$ have approximately the same magnitude (see equation (8)) so that the amplitude at a distance of, for example, one-quarter wavelength away from the generation a)

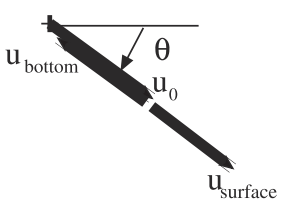

b)

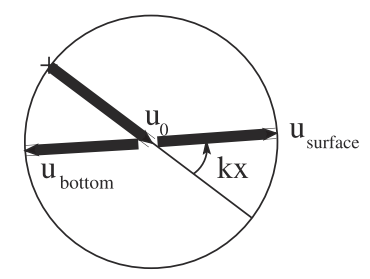

c)

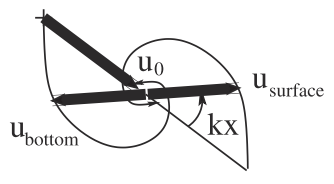

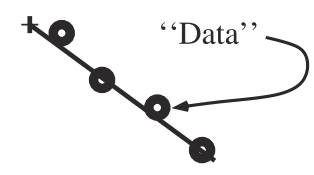
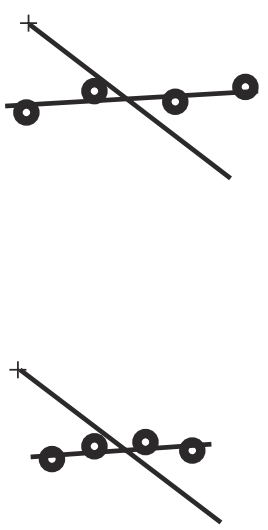

Figure 8. Spatial evolution of total velocity in the basin model. (a) Standing internal wave in which the phase angle of all velocities is the same and equal to the phase angle of the barotropic tide (denoted by $\theta$ ). On the right is shown a fictitious set of "data" from a standing wave system plotted on the complex plane. (b) Propagating internal wave. Here the amplitude/phase of measured velocities is along a line that does not go through the origin but can be rotated about its mean by angle $k x$ to touch the origin. (c) Propagating and decaying wave. Here the internal wave has decayed, and amplitudes approach that of the barotropic tide alone (see text for details). 
zone will have decayed to $\exp (-\pi / 2) \approx 0.2$ of its original amplitude. Once the wave has propagated far enough away from the sill, only the mean barotropic velocity structure remains.

[27] Comparing Figure 8 to the observations plotted in the same fashion in Figure $6 \mathrm{c}$, we immediately see that the major effect of the Victoria Sill is to generate an internal wave propagating northward. The observations lie along a bar rotated about $90^{\circ}$ or $1 / 4$ wavelength for the semidiurnal response and about half that for the diurnal response (the central point of the rotation represents the amplitude and Greenwich Phase of the barotropic tide). This represents the distance of the 1976 array from the "effective" sill. Since we expect the wavelength of the diurnal constituents to be about twice that of the semidiurnal constituents (see equation (8)), these two independent estimates of the sill location are consistent. Alternatively, one might consider the internal wave sensed at the mooring to have travelled for a time of one quarter the period of the semidiurnal tide from its source region; that is, the sensed internal signal is delayed 3 hours in relation to the barotropic tide. This matches the estimate illustrated in Figure 4.

[28] Also shown in Figure 6c are arcs representing the spatial evolution of an undamped (dotted arc) and strongly damped (dashed arc) response away from the sill. Although the dominance of the propagating signal implies that little energy is reflected back into this region from the northern sill (or indeed generated there), it appears that local dissipation is quite weak. The observed amplitudes of the baroclinic signal alone are still relatively large; that is, the diameter of the observed "bars" has not diminished to $\exp (-\pi / 4) \approx 0.5$ of its original size for the diurnal response or $\exp (-\pi / 2) \approx 0.2$ for the semidiurnal as would be the case if damping was strong, although for frequencies other than $\mathrm{M}_{2}$, they appear to be slightly smaller than would be expected in the undamped case.

[29] In theory a similar analysis of the 1996 alongchannel observations could be used to estimate the actual wavelength or phase speed of the signal by comparing the analyzed phase shift of the internal signal $k x$ with the known distance $x$. Unfortunately, the uncertainty in the harmonic analysis of those velocity records is large enough that no useful conclusion can be drawn in this way. Instead, we will attempt to use temperature records as a crude proxy for isotherm displacements $\eta_{b}$. Success is not guaranteed since there will be an ambiguity between the effects of horizontal advection of a spatially varying temperature field and vertical displacement due to internal waves.

[30] Internal wave displacements are found by integrating the vertical velocity, which is related to the horizontal velocity via the continuity equation. The dominant response is apparently a propagating wave, and therefore the isopycnal displacements are

$$
\begin{gathered}
\eta_{b}=i \frac{u_{0}}{\sigma} u_{x} \\
\eta_{b}=-u_{0} \frac{\sqrt{1+i R / \sigma}}{N} \sin \left(\frac{\pi z}{H}\right) e^{i k x}
\end{gathered}
$$

For right going free waves the isopycnal displacement is negative when the near-surface velocities are rightward. The presence of damping alters this situation by delaying the isopycnal displacements in relation to the horizontal velocity signal. Whereas with no damping the wave crests and troughs coincide with maxima and minima of horizontal baroclinic velocity, in strongly damped $(R / \sigma>1)$ systems they appear about one-eighth wavelength $\left(45^{\circ}\right)$ later. Note also that in strongly damped systems the amplitude of the displacement is larger and the wavelength shorter than for undamped waves of the same frequency. In weakly damped systems the wavelength is independent of damping.

[31] A harmonic analysis for temperature records at middepth shows that the Greenwich phase for the $M_{2}$ constituent increases by $144^{\circ} \pm 18^{\circ}$ from south to north $(14.4 \mathrm{~km})$. At $\mathrm{K}_{1}$ this increase is $100^{\circ} \pm 51^{\circ}$. Both values are consistent with a phase velocity of about $0.8 \mathrm{~m} \mathrm{~s}^{-1}$, not too different from a theoretical estimate $c=N H / \pi \approx 0.7 \mathrm{~m} \mathrm{~s}^{-1}$ using equation (8) and taking as typical a density gradient of about $2 \mathrm{~kg} \mathrm{~m}^{-3}$ over $270 \mathrm{~m}$. However, many other features of the phase do not match the picture we have derived above, and it is presumed that this occurs because of effects of horizontal advection. In particular, the phase of the $\mathrm{S}_{2}$ and $\mathrm{O}_{1}$ components, which in amplitude are not too much smaller that those of the $\mathrm{M}_{2}$ and $\mathrm{K}_{1}$ components, either decrease northward or exhibit unreasonably large changes. Also, the phase of the $\mathrm{M}_{2}$ and $\mathrm{K}_{1}$ displacements, lags that of the associated velocities by about $50^{\circ}$ and $20^{\circ}$, respectively. Such a phase lag implies through equation (11) a larger degree of damping than was found by analyzing velocity data alone.

[32] Figure 9 shows observed and modeled isopycnal displacements and velocities for two 25 hour periods. The first, 17 July 1996, is typical for a period of spring tides. The second, 23 July 1996, is a typical neap tide period. The modeled results were found by adding the fields for northward propagating waves generated by the four major components of the harmonic analysis (taking the amplitudes and Greenwich Phases from the central points of the rotations shown in Figure $6 \mathrm{c}$, assuming damping to be negligible and taking the effective sill distance to be onequarter (one-eighth) wavelength away for the semidiurnal (diurnal) components. The remaining free parameter is the wave number $k$ or, more conveniently, the wave speed $c=\sigma / k$, which is typically about $0.7 \mathrm{~m} \mathrm{~s}^{-1}$ for a density gradient of about $2 \mathrm{~kg} \mathrm{~m}^{-3}$ over $270 \mathrm{~m}$. This implies a wavelength of about $32 \mathrm{~km}$ for the semidiurnal response and $64 \mathrm{~km}$ for the diurnal waves. However, a qualitatively better picture results from taking $c=1 \mathrm{~m} \mathrm{~s}^{-1}$ (i.e., a wavelength of about $50 \mathrm{~km}$ for the semidiurnal response). In either case the effective sill location is centered somewhere slightly north of the shallowest part of the sill in the region of $\mathrm{km} \mathrm{30-35}$ in Figure 1d. The longer wavelength reduces the magnitude of isotherm displacements, making them more comparable with the observations, and also improves the along-channel correspondence of spatial features. In spite of this, modeled displacements are still quite large; isotherms sometimes rise above the surface and drop below the bottom! It appears that the large amplitude of the observed motions can be explained solely by the strength of the forcing and is not due to any additional effects of resonance. The comparison of along-channel velocities is not as good, although the major features, such as the rising of the zero-velocity region from the bottom 

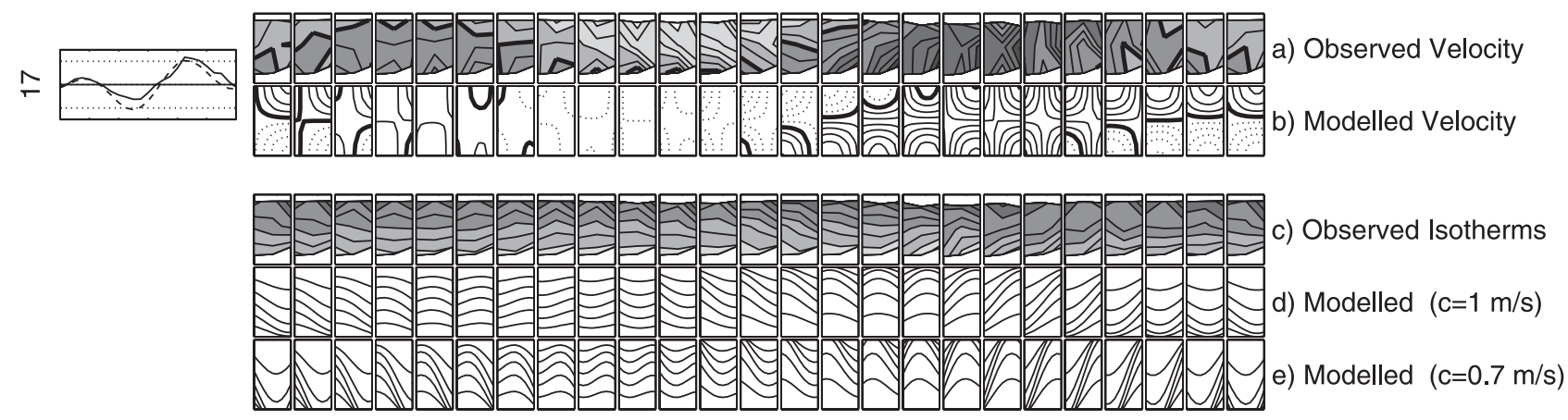

N
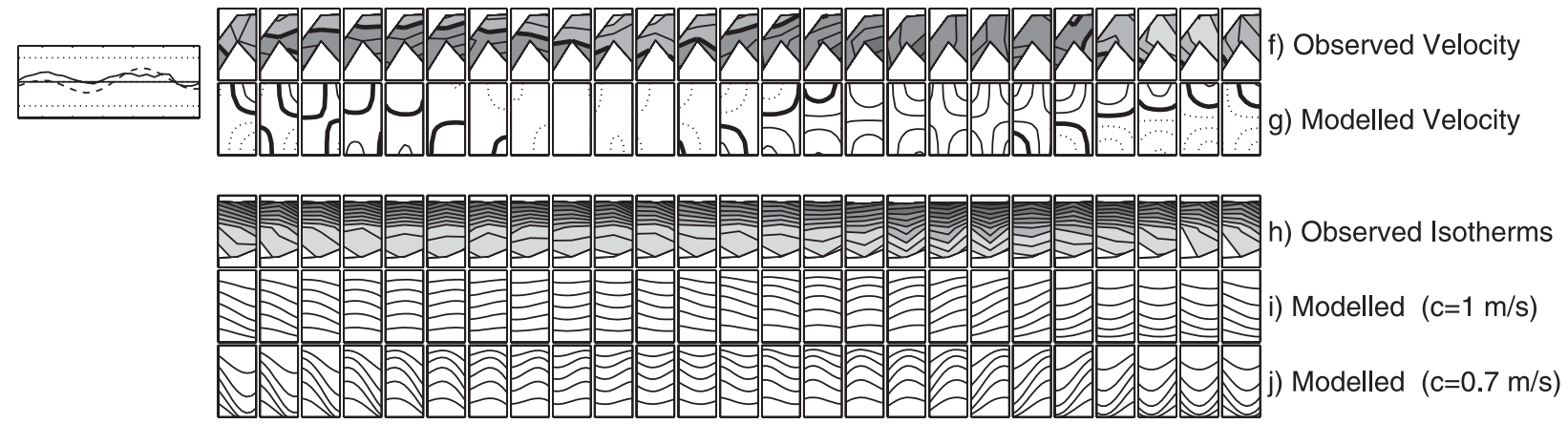

$$
\rightarrow \text { time (hourly blocks) } \rightarrow>
$$

Figure 9. Comparison between observed and modeled parameters for the along-channel section in hourly blocks as in Figure 5: (a)-(e) the daily cycle for a typical spring tide (17 July 1996) and (f)-(j) the daily cycle for a typical neap tide (23 July 1996). By this time two of the current meters no longer report speeds. Contour intervals for velocity comparisons are $0.25 \mathrm{~m} \mathrm{~s}^{-1}$, and the zero-velocity line is thick. Observed isotherm displacements are shown in comparison with two modeled results, one assuming a wave speed of $0.7 \mathrm{~m} \mathrm{~s}^{-1}$ (predicted from linear theory) and one assuming a wave speed of 1.0 $\mathrm{m} \mathrm{s}^{-1}$ (tuned to provide a qualitatively better result). At extreme left is a comparison between the observed mean tidal velocities (solid) and the four-component fit (dashed) for the relevant time periods.

during the transition to the strong flood tide, are well represented.

[33] Although the data are in general agreement with the linear wave hypothesis, several potentially important effects have been ignored. In particular, the problem was treated in a two-dimensional fashion, and the effects of the Earth's rotation were assumed negligible or irrelevant. Although there are no free-gravity waves at diurnal frequencies for this latitude, there is a Kelvin wave response, which will have a similar dispersion relation and along-channel structure, at least for the propagating solutions (basin modes will be more complicated). The deformation radius $c / f \approx 7 \mathrm{~km}$ is of the same order as the width of Haro Strait. Is it possible that a basin mode is being excited but that its form is more similar to an edge wave propagating in a counterclockwise direction around the basin? The apparent unidirectional nature of the wave observed in the deepest part of Haro Strait would then reflect the relative proximity of the eastern side and distance from the western side of Haro Strait. It is not possible to refute this supposition unequivocally, but at present it seems unlikely. The western side of Haro Strait is far more complex than the eastern side, with many shallow banks, islands, and troughs, and although the $\mathrm{S}$ mooring is quite far from the western side, the $\mathrm{M}$ and $\mathrm{N}$ moorings in 1996 are in much narrower parts of the channel in which such effects might be more visible. Harmonic analysis of the entire array of current meters deployed in 1976 (not shown) suggests that the amplitude of the internal oscillation does decrease westward away from the channel edge with approximately the deformation scale. However, it is possible that this cross-channel variation arises from purely inertial effects as the tidal stream moves northeastward from the Victoria Sill and is deflected northward by the coastline, i.e., that it arises from the geometry of the channel rather than from rotational effects.

\section{Conclusions}

[34] Although the baroclinic motions of the Haro Strait region are complex, some aspects of this behavior appear to be highly regular, remaining recognizably similar not only from tide to tide but also between spring/neap cycles and even from year to year (at least within the same season). The subtidal Eulerian estuarine flow appears to be fairly steady and, unlike the vertical stratification, does not undergo spring/neap cycling, at least during the limited period of the summer observations. At tidal frequencies a large internal wave is observed. This feature is generated at the Victoria Sill and propagates northward with only weak local damping. In spite of the lack of local damping the 
wave does not appear to be reflected at the northern end of Haro Strait, and although the Haro Strait basin is only about a wavelength long, little or no energy returns southward. Either damping is very strong in the northern end of this region (because of the right-angle bend in the channel and the shallow passages between islands to the north) or the Boundary Pass Sill is not large enough to form an effective barrier for wave propagation, in which case, the internal oscillation should propagate into the Strait of Georgia. This would occur in addition to the well-known nonlinear highfrequency internal wave packets generated at the Boundary Pass entrance [Shand, 1953; Gargett, 1976].

[35] These findings resulted from the interpretation of graphical diagnostics describing the essential behavior of a simple two-dimensional linear dynamical model in which the effect of sills was parameterized by an enforced coupling between the barotropic and first baroclinic mode in the vicinity of the sill such that near-bottom oscillations at that point were minimal (i.e., a blocking of tidal flow near the bottom). Although the linear model captures the gross details of the internal tide, the amplitude is large enough that nonlinear effects must play a role in the detailed evolution.

[36] Acknowledgments. Although the majority of this analysis was carried out at UBC under the support of Natural Sciences Engineering Research Council of Canada through grant OGP0194270, personnel from the Institute of Ocean Sciences, Sidney, B.C., were instrumental in making the original observations. I wish to thank in particular Les "Woody" Spearing for his sterling work in preparing, deploying, and recovering the 1996 moorings and Kevin Bartlett for processing this data. The 1976 data set was partly discovered by rummaging through IOS archives (with the help of Robin Brown) and partly resurrected from decaying magnetic tapes with the help of Grace Kamitakahara-King.

\section{References}

Baines, P. G., Topographic Effects in Stratified Flows, Cambridge Univ. Press, New York, 1995.

Crawford, W. R., Tidal mixing and nutrient flux in the waters of southwest British Columbia, in Tidal Hydrodynamics, edited by B. B. Parker, pp. 855-869, John Wiley, New York, 1991.

Farmer, D. M., and H. J. Freeland, The physical oceanography of fjords, Prog. Oceanogr., 12, 147-220, 1983.
Farmer, D. M., E. A. D’Asaro, M. V. Trevorrow, and G. T. Dairiki, Threedimensional structure in a tidal convergence front, Cont. Shelf. Res., 15, 1649-1673, 1995.

Farmer, D. M., R. Pawlowicz, and R. Jiang, Tilting separation flows: A mechanism for intense vertical mixing in the coastal ocean, Dyn. Atmos. Oceans, in press, 2002.

Foreman, M. G. G., R. A. Walters, R. F. Henry, C. P. Keller, and A. G. Dolling, A tide model for eastern Juan de Fuca Strait and the southern Strait of Georgia, J. Geophys. Res., 100, 721-740, 1995.

Gargett, A. E., Generation of internal waves in the Strait of Georgia, Deep Sea Res., Part A, 23, 17-42, 1976.

Gargett, A. E., and J. N. Moum, Mixing efficiencies in turbulent tidal fronts: Results from direct and indirect measurements of density flux, J. Phys. Oceanogr., 25, 2583-2608, 1995.

Godin, G., J. Candela, and R. de la Paz-Vela, On the feasibility of detecting net tranports in and out of Georgia Strait with an array of current meters, Atmos. Ocean, 19, 148-157, 1981.

Griffin, D. A., and P. H. LeBlond, Estuary/ocean exchange controlled by spring/neap tidal mixing, Estuarine Coastal Shelf Sci., 30, 275-297, 1990.

Herlinveaux, R. H., and J. P. Tully, Some oceanographic features of Juan de Fuca Strait, J. Fish. Res. Board Can., 18, 1027-1071, 1961.

LeBlond, P. H., D. A. Griffin, and R. E. Thomson, Surface salinity variations in the Juan de Fuca Strait: Test of a predictive model, Cont. Shelf. Res., 14, 37-56, 1994.

Linden, P. F., and J. E. Simpson, Modulated mixing and frontogenesis in shallow seas and estuaries, Cont. Shelf. Res., 8, 1107-1127, 1988.

Pawlowicz, R., A tracer method for determining transport in two-layer systems, applied to the Strait of Georgia/Haro Strait/Juan de Fuca Strait estuarine system, Estuarine Coastal Shelf Sci., 52, 491-503, 2001.

Pawlowicz, R., and D. M. Farmer, Diagnosing vertical mixing in two-layer exchange flows, J. Geophys. Res., 103, 30,695-30,711, 1998.

Shand, J. A., Internal waves in Georgia Strait, Trans. AGU, 34, 849-856, 1953.

Stacey, M. W., Some aspects of the internal tide in Knight Inlet, British Columbia, J. Phys. Oceanogr., 15, 1652-1661, 1985.

Stigebrandt, A., Vertical diffusion driven by internal waves in a sill fjord, J. Phys. Oceanogr., 6, 1105-1117, 1976.

Thomson, R. E., Tidal current and estuarine-type circulation in Johnstone Strait, British Columbia, J. Fish. Res. Board Can., 33, 2242-2264, 1976.

Thomson, R. E., Oceanography of the British Columbia Coast, Can. Spec. Publ. Fish. Aquat. Sci., vol. 56, Can. Dept. of Fish. and Oceans, Ottawa, Ont., 1981.

Webster, I., A physical oceanographic study of Haro Strait: A data summary and preliminary analysis, Contract Rep. Ser. 77-3, Inst. of Ocean Sci., Sidney, B.C., Canada, 1977.

R. Pawlowicz, Department of Earth and Ocean Sciences, University of British Columbia, 6270 University Blvd., Vancouver, B.C., V6T 1 Z4 Canada. (rich@ocgy.ubc.ca) 